\title{
Saudi Parents' Attitudes towards Using English as a Medium of Instruction in Private Primary Schools
}

\author{
Zahra Al-Qahtani \\ College of Languages and Translation, King Khalid University \\ PO box 9100, Abha 61413, Saudi Arabia \\ E-mail: zzzzz.07@hotmail.com \\ Abdul Wahed Al Zumor (Corresponding author) \\ College of Languages and Translation \\ PO box 9100, Abha 61413, Saudi Arabia \\ E-mail: aalzomr@kku.edu.sa
}

Received: 08-05-2015

Published: 01-01-2016
Accepted: 19-08-2015

doi:10.7575/aiac.ijalel.v.5n.1p.18
Advance Access Published: October 2015

URL: http://dx.doi.org/10.7575/aiac.ijalel.v.5n.1p.18

\begin{abstract}
This study sought to investigate Saudi parents' attitudes towards using English as a medium of instruction (EMI) in private primary schools. The study also attempted to find the reasons why Saudi parents prefer EMI private schools for their children. Additionally, it examined the effects of using EMI on children's Arabic language and culture, and their educational achievement in the next levels. The sample was 68 Saudi parents who have their children in a private primary school. The study used a questionnaire for data collection. It used a mixed design since data were analyzed using both quantitative and qualitative methods. Quantitative data were analyzed through statistical analysis (SPSS) while qualitative data were analyzed through content analysis using the categorization of themes. The results of this study showed that Saudi parents have positive attitudes towards using EMI in international private primary schools. Many Saudi parents prefer to send their children to EMI private primary schools, because they realize the importance of English as an international language, which can provide better opportunities for their children in the future. Also, they prefer to send their children to these schools, where English is used as a medium of instruction, because it is more effective if the child learned the language at an early age. However, some parents expressed a belief that English has negatively affected their children's Arabic language.
\end{abstract}

Keywords: English medium instruction, Bilingual education, Parents, Attitudes, Private schools

\section{Introduction}

As a result of globalization, English has become essential to economic, social and cultural development in a globalized world; this status of English as a global language has led it to become a medium of instruction in schools in many countries. Also, it has affected people's attitudes towards it. However, educationalists have warned of the effects of using English as a medium of instruction on the mother tongue.

In Saudi Arabia, although, Arabic is still used as the medium of instruction in all public primary schools, however, many private primary schools use English as a medium of instruction (EMI). Many Saudi parents today tend to send their children to private primary schools where English is the language of instruction. This would imply that parents are aware of the importance of English and the opportunities it provides for their children. However, theories of bilingualism emphasize the role of mother tongue competence in the development of the second language and the role of parents in their children's education (Cummins, 2001). So, if English is used as a medium of instruction in the initial stages, this may have some negative effects on the child's mother tongue (Arabic), their attitude towards their mother tongue and their culture.

It has been proven that parents' involvement in their children's education is essential for successful proficiency in both languages, the mother tongue and the second one (Al-Hussien, 2004). Therefore, parents' attitudes play an important role in their children's education. Their socioeconomic status and their educational experiences can affect their attitudes towards their child's mother tongue, the culture of the host country, and bilingual education.

The purpose of this study is to investigate parents' attitudes towards using English as the medium of instruction in private primary schools in Saudi Arabia and why they decided to send their children to EMI private schools.

\section{Literature Review}

This section introduces an overview of research related to parents' attitudes towards the use of English as a medium of instruction at primary level. The review has been organized into 4 subsections: 1) The role of the child's native language in the development of the second language at an early age, 2) The effects of using EMI on children's mother 
tongue and culture, 3) Parental involvement and attitudes of parents and their impact on their child's education, 4) English status in Saudi Arabia.

\subsection{The Role of the Child's Native Language in the Development of the Second Language at an Early Age}

Bilingualism is one of the major issues in the contemporary world for economic and social reasons and because of the diverse cultures living together in some parts of the world. Children come to speak more than one language with different cultural backgrounds. Therefore, educationalists realize its importance and try to find the best way of teaching in bilingual contexts. To examine the role of the child's native language in the development of the second, the threshold hypothesis, the linguistic interdependence hypothesis, and the distinction between 'basic interpersonal communicative skills' (BICS) and 'cognitive/academic language proficiency' (CALP) are used to provide insights on the importance of the child's native language for successful L2 development.

First, the threshold hypothesis explains both negative and positive cognitive and academic consequences of bilingualism (as cited in Hanani, 2009). The hypothesis states two distinct thresholds of competence in two languages and the contradiction between them. Negative cognitive consequences are found when minimum competence is found in both languages. This is the lower threshold. Positive cognitive consequences are found when maximum level of competence is found in both languages. This is the higher threshold which demonstrates that bilinguals are cognitively better compared by monolinguals. In between these two thresholds, a bilingual with one dominant language and a weak second language demonstrates neither negative nor positive cognitive effects. The hypothesis emphasizes that children's native language is important for the development of the second language.

Second, the linguistic interdependence hypothesis shows that there is an interaction between the development of a child's literacy skills in a first and second language (as cited in Hanani, 2009). There are two aspects of this interaction. On the one hand, children who are exposed to rich linguistic input of their first language outside the school (e.g., at home) are better at acquiring a second language. On the other hand, children who are not exposed to rich linguistic input of their first language are having a bad effect on the development of their L1 when exposed to a second language which in turn slows down second language development. So, first language development is prior to the development of the second in terms of a common underlying proficiency. This hypothesis predicts the outcomes of second language learning alongside with first language of children.

Third, the distinction between 'basic interpersonal communicative skills' (BICS) and 'cognitive/academic language proficiency' (CALP) (as cited in Hanani, 2009). This distinction refers to two broadly distinct varieties of language use: the first, BICS, is richly embedded in context where the comprehension of language is supported by cues from the situation of use such as non-verbal gestures and feedback from the interlocutor; the second, CALP, is "disembedded" from contextual support, and is often used for purposes that are cognitively more demanding. This distinction has provided the basis for understanding why children often lag behind in academic performance despite apparent linguistic fluency (as cited in Hanani, 2009). The interpretation of such findings is that the early fluency demonstrated is often of the BICS variety, with children requiring a much longer time (five-seven years are often cited in the literature) for their CALP to take place. These considerations have justified suggestions to delay the transition of language, of children from first language to second language instruction.

Thus, scholars emphasize the use of the mother tongue in the primary stages of education in order to improve the quality of education as well as to preserve the language, and to provide a solid foundation for the students' native Language.

Finally, Cummins (2001) argued that the context surrounding the students, including parents and schools can play a major role in reaching the achieved level of performance in L1. He suggests that children's mother tongue should be reinforced at first place in order to learn a second language which depends on children's first language proficiency. So, parents play a big role in providing children with enough exposure to L1.

\subsection{The Effects of Using EMI on Children's Mother Tongue and Culture}

Globalization has emphasized the use of English and governments are restructuring their educational, economic and social policies to cope with international trends. English becoming the medium of instruction in many private and public schools in the Arab world context needs to be taken into consideration especially in light of today's heightened sentiments of nationalisms and instability (Ahmad, 2010). This impacts education in which English becomes the medium of instruction in Arabic countries including Saudi Arabia. English is used as a medium of instruction in many private primary schools in Saudi Arabia. However, there are some consequences that might happen if English was used as the only medium of instruction.

Many of the studies available in the literature deal with EMI in tertiary education. These studies have highlighted some of the challenges associated with the EMI model at the tertiary institutional level, namely the impact of English language proficiency on academic performance and the exclusion of the L1 in the EMI model (Mouhanna, 2010). Children's mother tongues are easily damaged and lost in their early years of school. Fillmore (1991) found that the younger the children are, when they begin schooling, the greater the impact of English is on their first language and the greater the degree of language loss is. In such a situation, children gradually shift to the second language until they cease to use their mother tongue (Fillmore, 1991). In this case, Arabic is threatened when English is used as a medium of instruction in primary schools. 
One of the sequences when emphasis is on English is that children who attend English medium schools have the impression that their mother tongue is not valued. This negative attitude towards their Arabic language will imply low self-esteem. They might feel ashamed of being part of that belittled language and culture (Hanani, 2009).

This happens when Arabs' children speak English at home more fluently than their mother tongue, but parents speak Arabic primarily. "That has an impact on the parent-child interaction - They feel different from their parents and it affects the harmony [of the relationship],"said Al Ghorani (as cited in Naidoo, 2011). On the other hand, bilingual education programs that are properly established and correctly run can provide successful bilingual literacy in both mother tongue and second language (Hanani, 2009).

\subsection{Parental Involvement and Attitudes of Parents and their Impact on their Children's Education}

Parents' involvement in children's education is essential for successful proficiency in languages, the native language and the second language. In bilingual communities where a second language is the medium of instruction, Baker and Genesee (Baker, 2001; Genesee, 1999) argued that parents' involvement in children's lives is critical in facilitating their development, including greater academic success in bilingual programs (as cited in Hanani, 2009). Parents who enroll their children in schools where a second language is the medium of instruction need to take part of the responsibility (Fillmore, 2000).

Moreover, parents' involvement in their children's education from an early age was proved to enhance better outcomes, especially in terms of cognitive development. The home learning activities conducted by parents are more significant for children's intellectual and social development than parental occupation, income or education. In a large- scale longitudinal study (EPPE) of 3000 children, tracing the development of children from age three through to the age of 10, the study examined the influence of parental involvement on children's attainment while considering other background factors such as family socio-economic status, mother's education and income. The study has found that parents' involvement in home learning activities makes an important change to children's academic achievement (Sammons, 2007).

There is evidence that parents' attitudes have an impact on their children's educational achievement. International studies show that parents' education influences expectations. So that parents with higher education have higher expectations of children's achievement and consequently have higher attaining children. Also, U.S studies found that parents with high aspiration are more likely to be involved in their children's education. Gutman and Akerman (2008) found that most parents have high aspirations for their children, however, as the children grow up these aspirations become less because of economic constraints and the availabilities of opportunities. They also found that regardless of socioeconomic background, aspirations can be stronger predictors of achievement for children, although children from advantaged socio-economic backgrounds are more likely to be influenced by such aspirations (Davis-Kean \& Schnabel, 2001).

Parents' attitude towards their child's mother tongue affects their education success. Their involvement and encouragement can influence them to have positive attitudes towards learning their mother tongue. They can increase their children's self-confidence and pride about who they are and help them practice their culture. They can provide resources to support their involvement in learning their mother tongue. In fact, the positive attitude that children hold for learning their mother tongue results from the power of the relationship between them and their parents, and to what extent they are proud of their identity and culture (Hanani, 2009).

Parents' attitudes towards the culture of the host country have also a great effect on their children's second language learning as well as learning different cultures. Shin (2000) said that using the first language at home is essential for the child's literacy development in school, and that involving the native language of parents in their children's education has a positive impact on their academic development (as cited in Al-Hussein, 2004). This attitude can be either passive or active, i.e., children have a better foreign language achievement if their parents have an active attitude towards this foreign language, even if these parents do not speak the language and the opposite is correct, if the parents have a passive attitude towards the foreign language. According to Rosenbusch (1987), parents can show their positive attitudes towards the learning of a foreign language by being part of their child's learning at home and at school (as cited in Al-Hussein, 2004).

Some parents have the misconception that children in bilingual education programs who receive instruction in their native language are not learning English proficiently. While, some others know that giving instruction in both the native language and English helps children become proficient in English (Al-Hussein, 2004). For example, in Zimbabwe, parents don't support local languages in bilingual- bicultural education in primary schools. Their attitude to L1 is very poor. Most parents in Zimbabwe think of English as a way to reach employment and education is equated with the proficient use of English. They encourage their children to use English in daily life situations and neglect primary languages (Peresuh, M., \&Mashukn, J., 2002). Also, in interviews with some immigrant Saudi parents in the US, they said that they want their children to learn only English in school and to speak only their first language at home (AlHussein, 2004).

Parents have different views towards bilingual education, some are positive while others are negative. Parents are against bilingual education only when the native language is the only language used for instruction. But when bilingual education programs use the native language as well as English, parents tend to have a more positive view. This positive view has a great effect on the success of the program (Al- Hussein, 2004). A study by Youssef and Simpkins in 1985 showed that $90 \%$ of Arab parents supported their children's bilingual education, and wanted them to continue with 
these programs. The reason for this is that these classes are more accepting than regular classes. The majority of parents also expresses their needs to have an emphasis on teaching the Arabic language and culture in schools. Youssef and Simpkins (2004) also found out that only 59\% of the parents believed that they have a major role in their children's education. They also concluded that "these parents view their language and culture as an asset to both themselves and their children" (as cited in Al-Hussein, 2004). Another study in Sri Lanka shows positive parents' attitudes towards using English as a medium of instruction in two schools in Jaffna. Parents understand the importance of English because it provides better opportunities for their children. They think that high proficiency in English open new gates to fulfill the demands of the globalized world (Thirunavukkarsu, 2011).

Moreover, Qian (2008) claimed that parents are aware that proficiency in the English language "has always been an important factor for new university graduates in securing employment" (p. 100). Parents who seek a better educational program and a better future for their children give poor reputation of public schools in which Arabic is the only medium of instruction. As a result, in UAE, for example, many parents are transferring their children to English schools looking for better quality of education. They look for effective bilingual programs in developing their children's biliteracy in both English and Arabic (as cited in Hanani, 2009).

\subsection{The status of English in Saudi Arabia}

English is considered as a foreign language in Saudi Arabia. In this regard, one might refer to Kachru's concept of three concentric circles, which represents "the types of spread, the patterns of acquisition and the functional domains in which English is used across cultures and languages." The "inner circle" is comprised of such countries as the UK, the US, Canada, Australia and New Zealand, where English is the primary language. In the "outer circle", English is used quite widely for internal (intranational) purposes; examples are India and Singapore. As an EFL country, Saudi Arabia belongs to the third circle, the "expanding circle", where English is used as a tool for communication, trade, business, diplomacy, travel, and as a medium of instruction in higher education.

English language is used as a medium of instruction in many universities in Saudi Arabia in teaching subjects, such as science, medicine, dentistry, engineering and computers and to a lesser extent by others. One of the conditions for acceptance into schools such as Medicine and Dentistry is English language proficiency. The need for the language is even greater at higher degree level; it is essential in most majors. In Saudi Arabia, Arabic is the language of instruction in many public schools at all levels (primary, intermediate and secondary), however, many private international primary schools in Saudi Arabia use English as a medium of instruction in order to help children to obtain proficiency in English.

\subsection{Saudi Language Policy}

Language policy is an important component in drafting education policies in any country. Phillipson and SkutnabbKangas (1996) defined language policy as "decisions on rights and access to languages and on the roles and functions on particular languages and varieties of language in a given polity. Such policies, and the decisions that highlight them, may be more or less overt or covert." In Saudi Arabia such policies are rather covert due to the fact that Arabic is the only spoken language (the national language and the official language). Moreover, the Saudi educational system is mainly influenced by religion because Islam is the only religion practiced in the country. The government tries to preserve the holiness of the religion, culture, and the Arabic language itself since Arabic is the language of the holy Quran. Therefore, it is widely believed that the use of EMI at school level could threaten the religious and cultural identity of the country. The Saudi education policy has stated five articles (24, 46, 50, 114, and 140) related to language policy (Al-Abdaly, 2012). These articles indicate that all levels of education should be taught in Arabic. In 2003, the Saudi ministry of education makes the decision of teaching English as a required subject in the public schools starting from grade 6. The next year, the teaching of English began from grade 5 (as cited in Ebad, 2014). Now, the teaching of English starts from grade 4. This phenomenon is moving at a very slow pace because of specific factors mentioned above. On the other hand, many private international schools across the kingdom are using EMI in their policy, especially those that cater for children educational needs. In these schools, all teaching activities are conducted in the English Language. Although, Arabic language modules are also used in parallel, the focus is more onto English. Thus, many Saudi parents today thrive to enroll their children in these private international primary schools to increase English language proficiency of their children.

\section{Research Problem}

The increasing emphasis on English as an international language and its dominance in almost every aspect of life especially in the job market has led many Saudi parents to prefer private primary schools, where English is adopted as the medium of instruction, on public primary schools. This would imply that parents are aware of the importance of English and the opportunities it provides for their children. The increasing emphasis on English seems to affect the use of the Arabic language among children. Children who attend these private schools are challenged by the use and the presence of the English language which is likely to have a negative impact on children's mother tongue (Arabic), their attitude towards their mother tongue and their culture. This study intends to explore Saudi parent's attitudes towards the use of English as a medium of instruction in private primary schools and its possible impact on their children's mother tongue (Arabic).

\section{Methodology}

The methodology of the study uses mixed design since it involved both quantitative and qualitative methods of data collection and analyses. Particularly, the study adopted a questionnaire with Likert-scale statements and three open- 
ended questions. The data were analyzed using descriptive statistics and content analyses. This section outlines the research problem, research questions, participants, instrument, procedure, and data analysis.

\subsection{Objectives and research questions}

The objective of this study is to investigate the attitudes of male and female Saudi parents towards using English as a medium of instruction in (Talla'aAlmostagbal) international private primary school in the Southern region of Saudi Arabia, Abha. More specifically, the study aims at investigating parents' opinions about the importance of children learning English, primary level as the suitable age for their children to learn English and the reasons for Learning English at an early age. Also, it examines how parents' educational experience and socio-economic status, and their attitudes towards using EMI in private schools, the western culture and their native language will affect their child's education.

Therefore, this study attempts to find answers to the following questions:

1. What are parents' attitudes towards using EMI in international private primary schools?

2. Why do many Saudi parents choose to send their children to EMI international private schools from an early age (primary level)?

3. What are the potential effects of using EMI on children's Arabic language and culture, and on their educational achievement in next levels?

\subsection{Participants}

The sample of the present study included Saudi male and female parents who have children studying in (Talla'aAlmostagbal) private international school in the Southern region of Saudi Arabia, Abha. A number of 100 Saudi parents were contacted through their children and asked for their consent to participate in this study, of whom 68 completed the survey. Arabic translation of the questionnaire was provided because all parents are Saudi nationals whose mother tongue is Arabic (see Appendix B). The age of the 68 participants ranges between 17 and 55 years old. The majority of participants has learnt English at age 13, and some of them at 12.The sample included 12 male participants (17.9\% of the participants) and 55 female participants $(82.1 \%$ of the participants). Only one participant did not respond to this item (see Table 1). The participants were asked to provide their level of English (poor, intermediate, advanced) based on their self-reporting. Those who have poor level were 4 (6.0\% of the participants), and those who said intermediate were 31 (46.3\% of the participants), while 32 (47.8\% of the participants) were advanced (See Table 2).

Table 1. Sample description in light of the gender

\begin{tabular}{lllll}
\hline Gender & Frequency & Percent & Valid Percent & Cumulative Percent \\
\hline Male & 12 & 17.6 & 17.9 & 17.9 \\
Female & 55 & 80.9 & 82.1 & 100.0 \\
\hline Total & 67 & 98.5 & 100.0 & \\
\hline
\end{tabular}

Table 2. Sample description in light of participants' English level

\begin{tabular}{lllll}
\hline English level & Frequency & Percent & Valid Percent & Cumulative Percent \\
\hline Poor & 4 & 5.9 & 6.0 & 6.0 \\
Intermediate & 31 & 45.6 & 46.3 & 52.2 \\
Advanced & 32 & 47.1 & 47.8 & 100.0 \\
\hline Total & 67 & 98.5 & 100.0 & \\
\hline
\end{tabular}

\subsection{Instrument}

The instrument for this study was a questionnaire of 33 items, which consisted of four demographic questions and 26 quantitative, attitude questions as well as three qualitative open-ended questions.

The twenty- six questions employed a 5 point Likert Scale ranging from (1) "Strongly Disagree" to (5) "Strongly agree." The Likert scale items were stated with regard to the following constructs: around parents' attitudes towards the importance of English for their children, parents' attitudes of primary level as the suitable age for their children to learn English, reasons of learning English at an early age (primary level) from parents' perspective, parents' attitudes towards using EMI in private primary schools, parents' attitudes towards the effect of EMI on children's educational achievement in next levels, parents' attitudes towards the effect of EMI on children's Arabic language and culture. Three open-ended questions were asked to provide detailed information about certain aspects of participants' perceptions of using English as a medium of instruction (see appendix A). 
The instrument for this study was a questionnaire distributed in Arabic language, because the participants were Saudi parents whose mother tongue is Arabic. After the green light to distribute the survey was given by the supervisor, participants received the questionnaires through the principle department of the school. They were informed in the questionnaire that the purpose of the study is purely academic and asked for their consent to participate in the study. The participant received the questionnaire through their children. The process of distributing the questionnaires and receiving them back took 10 days. The purpose of the study was explained to participants as purely academic and they were informed that their participation in the study was totally voluntary.

\subsection{Data analysis}

The data that was analyzed by using descriptive statistics with the results of each area of interest manifested in summary tables and figures. The mean scores of items in each construct (parents' attitudes towards the importance of English for their children, parents' attitudes of primary level as the suitable age for their children to learn English, reasons of learning English at an early age (primary level) from parents' perspective, parents' attitudes towards using EMI in private primary schools, parents' attitudes towards the effect of EMI on children's educational achievement in next levels, parents' attitudes towards the effect of EMI on children's Arabic language and culture) were calculated. The statistical analysis was calculated by using SPSS software. Content analysis was used to analyze the three open-ended questions in the questionnaire.

\section{Results}

This study aimed at investigating attitudes of Saudi parents towards the use of English as a medium of instruction in "Talla'aAlmostagbal" international private primary school. Specifically, the participants' attitudes were examined under six constructs: 1) Attitudes towards the importance of English for their children, 2) Attitudes of primary level as the suitable age for their children to learn English, 3) Reasons of learning English at an early age (primary level) from parents' perspective, 4) Attitudes towards using EMI in private primary schools, 5) Attitudes towards the effect of EMI on children's educational achievement in next levels, 6) Attitudes towards the effect of EMI on children's Arabic language and culture. These aspects form the quantitative part of the study and were analyzed by using statistical descriptive analysis. The study also contains three open-ended questions as the qualitative part of the study.

\subsection{Results of Descriptive Questions}

The first research question was formulated to investigate the participants' attitudes and perceptions towards the use of EMI in private primary schools. The second attempted to find reasons behind the preference of many Saudi parents of EMI private primary schools for their children. The third question's purpose was to examine the influence of EMI on children's Arabic language and culture, and on their educational achievement in the next levels. Results are shown in Tables 3, 4, 5, 6, 7, and 8 .

The criteria used to interpret participants' responses followed the norms (Strongly disagree $=1-1.8)$, (Disagree=1. 82.6), (Somewhat agree=2. 6-3.4), (Agree=3. 4-4.2), (Strongly agree=4. 2-5).

The first set of statements aimed at investigating participants' attitudes towards the importance of English for their children (see Table 3).

Table 3. Attitudes towards the importance of English for children

\begin{tabular}{llllll}
\hline Statements & $\mathrm{N}$ & Minimum & Maximum & Mean & Std. Deviation \\
\hline a6 & 67 & 1 & 5 & 3.39 & 1.507 \\
a7 & 68 & 3 & 5 & 4.63 & .689 \\
a8 & 68 & 2 & 5 & 4.53 & .819 \\
\hline
\end{tabular}

Statement 6, English Language is important nowadays, indicated moderate agreement among the participants $(\mathrm{N}=67)$, with a Mean of 3.39 out of 5. It seems that participants consider English language to be of moderate significance nowadays. Unlike statement 6, statement 7, I believe that it is important to teach my children English language because it is a global language, elicited the highest agreement with a Mean score 4.63, suggesting that most of the participants recognize the importance of teaching their children the English language because it is a global language. Statement 8 , Those of my children who studied English at an early age are better in their academic achievement than those who studied it at later stages, also revealed strong agreement among the participants $(\mathrm{N}=68)$, with a Mean of 4.53. These findings are shown in Figure 1, illustrating that $67.65 \%$ of the participants considered English as an important language for their children to learn, with scores ranging between 4 and 5, of which $41.18 \%$ scored between 4.67 and 5 on the attitude scale. 


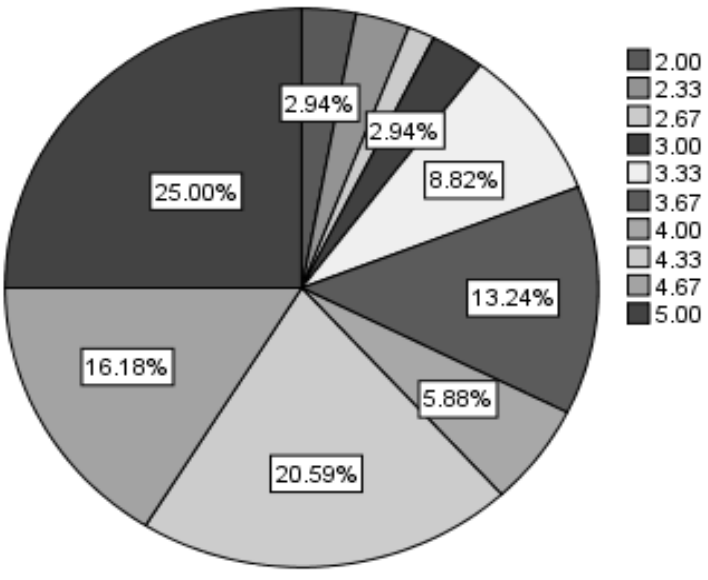

Figure 1. Distribution of scores total for attitudes toward the importance of English for children

The second set of statements aimed to examine the participants' attitudes of primary level as the suitable age for their children to learn English (see Table 4).

Table 4. Attitudes toward learning English at an early age (primary level)

\begin{tabular}{llllll}
\hline Statements & N & Minimum & Maximum & Mean & Std. Deviation \\
\hline a9 & 68 & 1 & 5 & 4.47 & 1.058 \\
a10 & 67 & 1 & 5 & 4.49 & .990 \\
a11 & 66 & 2 & 5 & 4.68 & .660 \\
\hline
\end{tabular}

For statement 9, I believe that the suitable age for learning English starts from first grade in primary schools, the participants $(\mathrm{N}=68)$ have revealed a strong agreement with a Mean score 4.47 out of 5 . In this sense, it appears that the majority of participants agree that first grade in primary schools is the suitable age for learning English. The second statement, Children who learn English at an early age (from seven years old) are better than those who learn it at ten or above, also elicited strong agreement among participants $(\mathrm{N}=67)$, with a Mean of 4.49 . They expressed a belief that children who study English at an early age are better than those who study it lately at ten or above. The participants showed that strongest agreement with statement 11, I believe that learning English at an early age from the primary level is easier than learning it from an intermediate level, giving a Mean score of 4.68. This indicated that the participants appear to believe that learning English at an early age is easier more than if children learn it from an intermediate level. These findings are demonstrated in Figure 2, showing that $82.34 \%$ of the participants have emphasized learning English at an early age, scored between 4 and 5, with $67.64 \%$ between 4.67 and 5 .

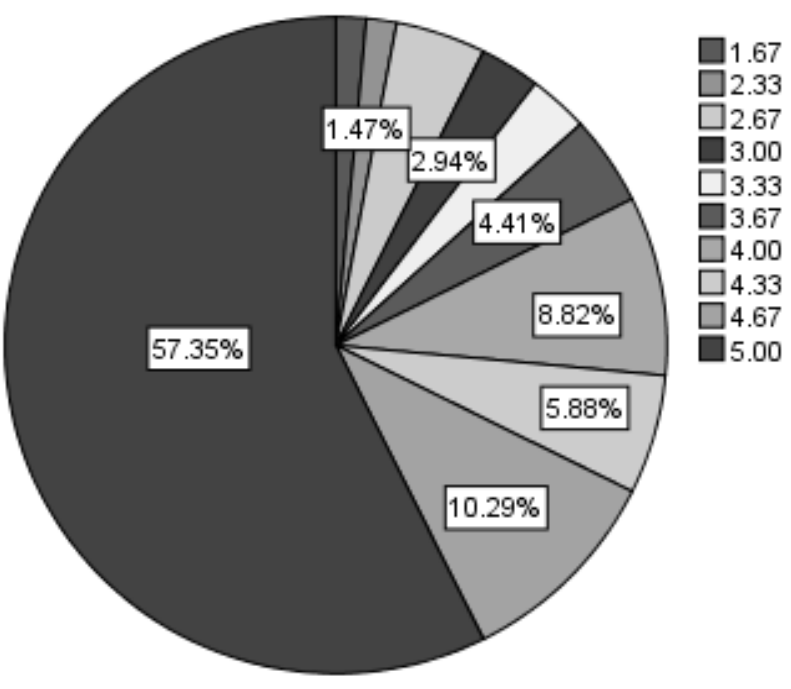

Figure 2. Distribution of scores total for attitudes toward learning English at an early age 
The third set of statements aimed at investigating the reasons of learning English at an early age (primary level) from parents' perspective (see Table 5).

Table 5. Reasons of learning English at an early age (primary level) from parents' perspective

\begin{tabular}{llllll}
\hline Statements & $\mathrm{N}$ & Minimum & Maximum & Mean & Std. Deviation \\
\hline a12 & 67 & 1 & 5 & 3.73 & 1.366 \\
a13 & 66 & 1 & 5 & 4.29 & .957 \\
a14 & 66 & 1 & 5 & 3.62 & 1.322 \\
a15 & 67 & 1 & 5 & 4.30 & .888 \\
\hline
\end{tabular}

Moderate agreement was given by participants $(\mathrm{N}=67)$ for statement 12 , I think the English language is more useful than Arabic because it provides better chances for employment, and statement 14, Children who have proficiency in English attained a higher social status, yielding a Mean score of 3.73 and 3.62 respectively. In other words, the majority of participants appeared to see English as more useful than Arabic in terms of employment and social status. Nevertheless, participants $(\mathrm{N}=66)$ revealed a strong agreement with statement 13 ; I believe that being proficient in English is one of the requirements for succeeding in life, with a Mean of 4.29. This implies that the participants consider knowledge of English as essential in order to have a successful life. Additionally, participants (N=67) strongly agreed with statement 15, Children learn English at an early age in order to avoid communication problems with others in the future, e.g., travelling abroad, with a Mean of 4.30. These findings are demonstrated in Figure 3, showing that 51.47\% of the participants scored between 4 and 5, with 20, $59 \%$ between 4.75 and 5 .

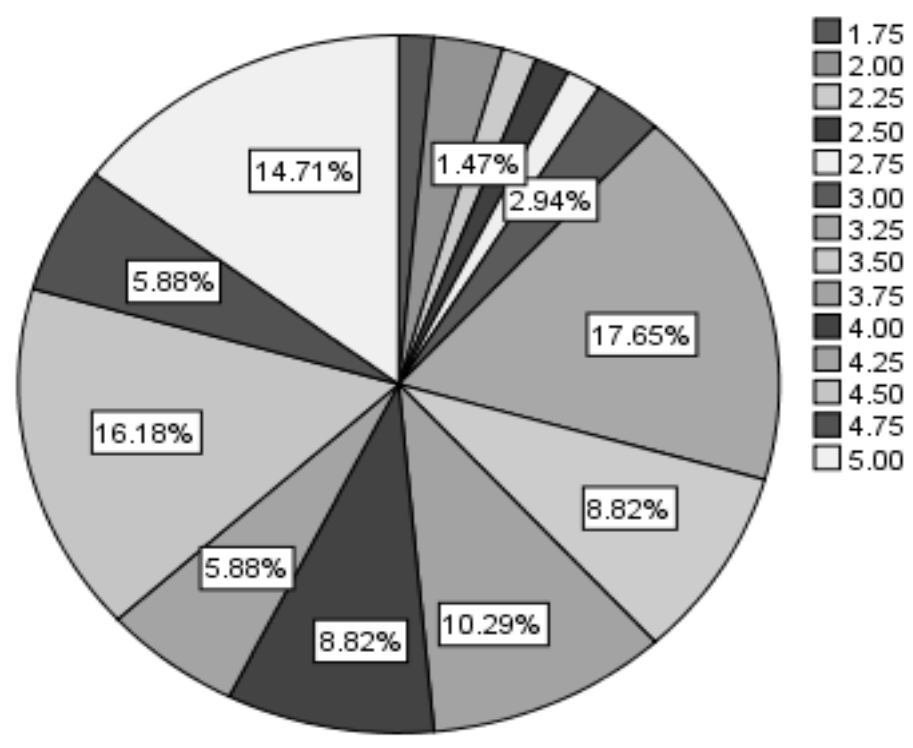

Figure 3. Distribution of total scores for reasons of learning English at an early age (primary level) from parents' perspective

The fourth set of statements aimed to examine participants' attitudes towards using EMI in private primary schools (see Table 6).

Table 6. Attitudes towards using EMI in private primary schools

\begin{tabular}{llllll}
\hline Statements & $\mathrm{N}$ & Minimum & Maximum & Mean & Std. Deviation \\
\hline a16 & 67 & 1 & 5 & 3.54 & 1.318 \\
a17 & 67 & 1 & 5 & 3.81 & 1.258 \\
a18 & 68 & 1 & 5 & 4.18 & 1.050 \\
a19 & 66 & 1 & 5 & 3.64 & 1.432 \\
a20 & 67 & 2 & 5 & 4.58 & .678 \\
a21 & 67 & 1 & 5 & 3.40 & 1.303 \\
a22 & 64 & 1 & 5 & 2.42 & 1.343 \\
\hline
\end{tabular}


Statement 16, It is important for my children to be enrolled in international private schools where English is the medium of instruction even if I have a low income, as well as, statement 17, I believe that employed and educated mothers are more likely to send their children to study in international private schools where English is the medium of instruction, revealed moderate agreement, with a Mean between 3.54 and 3.81. These two statements focused on the socio-economic status of the family. The statistics showed that the participants $(\mathrm{N}=67)$ agreed to some extent that the socio-economic status of the family, such as family income and parental occupation can influence the parents' choice of EMI private primary schools for their children.

Statements 18, 19, and 20 focused on participants' perceptions of EMI private primary schools, where English is used as a medium of instruction. As seen in table 6, statement 18, It is better for my child to join EMI schools, and statement 20, I think that using both Arabic and English as mediums of instruction in the primary level is more useful, elicited strong agreement among the participants, with statement 20 achieving the highest Mean= 4.58. However, statement 19 , I think that children who study in EMI schools are better than those who study in public primary schools where Arabic is the language of instruction, showed a moderate agreement with a Mean of 3.64. This indicates that most of the participants $(\mathrm{N}=66-68)$ prefer to enroll their children in EMI private primary schools where both Arabic and English are the mediums of instruction. According to statement 19, it appeared that participants believe that EMI private schools are better than public schools.

The next two statements concentrated on participants' attitudes towards teaching all subjects in English. Statement 21, it is preferable to teach all subjects in English in order to increase my child's proficiency in English, revealed a moderate agreement among participants with a Mean of 3.40. On the contrary, statement 22, teaching all subjects in English means a lower level of academic achievement, showed that the participants slightly agreed, yielding a Mean score of 2.42. Regarding this point, participants preferred that all subjects taught in English in order to increase their children's proficiency in English.

Overall, participants expressed strong preference of EMI private schools where both Arabic and English are used as mediums of instruction, and preferred teaching all subjects in English in order to increase their children's proficiency in English. Figure 4 showed that $33.81 \%$ of participants scored between 4 and 5, with $22.05 \%$ between 4.29 and5.

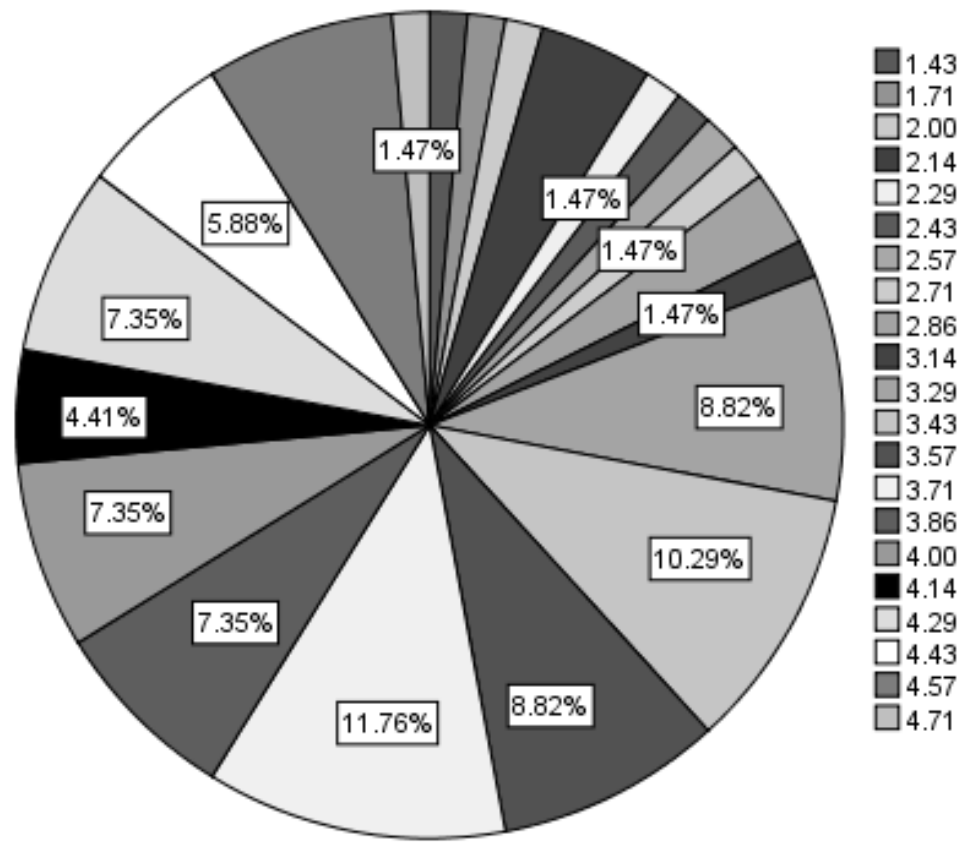

Figure 4. Distribution of scores total for attitudes towards using EMI in private primary schools

The fifth set of statements aimed to examine the participants' attitudes towards the effect of EMI on children's educational achievement in next levels (see Table 7).

Table 7. Attitudes towards the effect of EMI on children's educational achievement in next levels

\begin{tabular}{llllll}
\hline Statements & $\mathrm{N}$ & Minimum & Maximum & Mean & Std. Deviation \\
\hline a23 & 67 & 1 & 5 & 4.13 & 1.028 \\
a24 & 68 & 1 & 5 & 4.22 & .895 \\
a25 & 68 & 1 & 5 & 3.49 & 1.215 \\
a26 & 68 & 1 & 5 & 2.76 & 1.317 \\
\hline
\end{tabular}


Strong agreement was found among participants $(\mathrm{N}=67)$ for statement 23 , Children who learn English at an early age (from primary stage) are more successful in later stages than their peers who didn't study at an early age, and statement 24, Children who learn English at an early age will have a better understanding capacity, gain more knowledge and develop cultural awareness, with a Mean score ranging between 4.13 and 4.22. In other words, the majority of participants appeared to agree that learning English at an early age will influence positively their success in later stages, their understanding capacity, and their cultural awareness. However, statement 25, Children who study using English language has a higher level of performance and academic achievement than those who use Arabic language, drew an indication of a moderate agreement among the participants $(\mathrm{N}=68)$, with a Mean of 3.49. This suggests that not all of the participants relate Learning English with higher levels of performance and academic achievement. On the contrary, the participants slightly agreed for statement 26; I find that the child who has a poor level of English proficiency is less successful than the other children, yielding a Mean of 2.76. In this sense, most of the participants expressed a belief that the child with poor level of proficiency is not less successful compared with other children. All in all, participants expressed strong agreement to learning English at an early age which will influence positively children's educational achievement in the next levels. Figure 5 indicates that $42.81 \%$ of the participants scored between 4 and 5, and $32.52 \%$ between 4,25 and 5 .

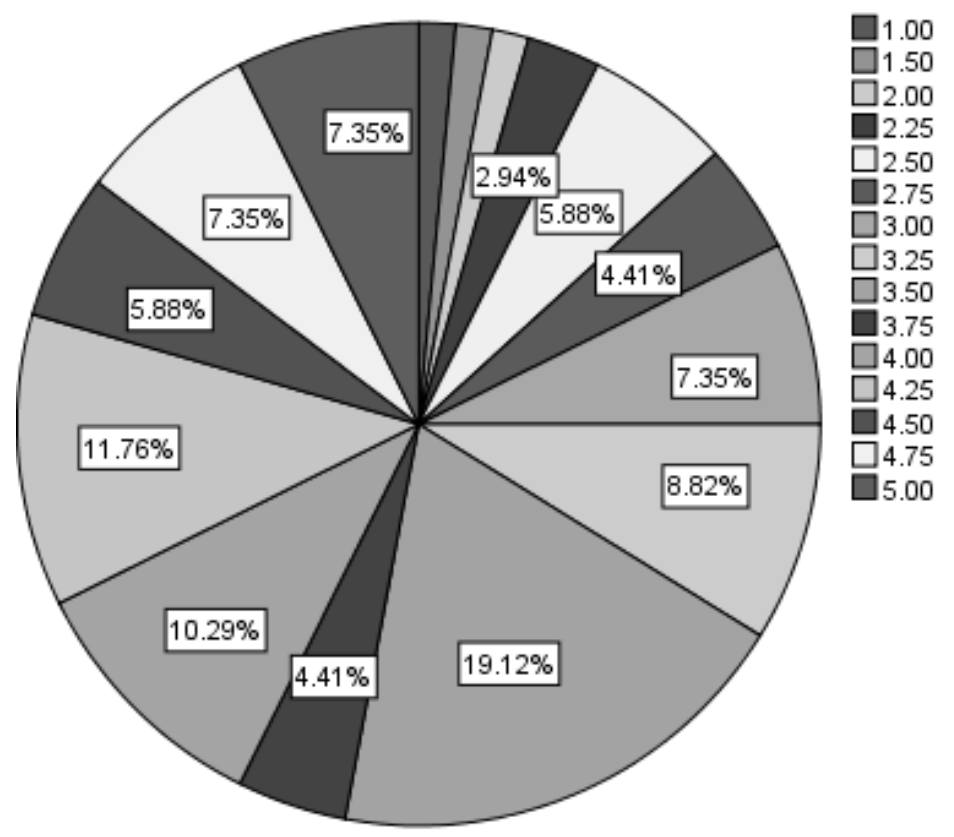

Figure 5. Distribution of scores total for attitudes towards the effect of EMI on children's educational achievement in next levels

The sixth set of statements aimed at investigating the participants' attitudes towards the effect of EMI on children's Arabic language and culture (see Table 8).

Table 8. Attitudes towards the effect of EMI on children's Arabic language and culture

\begin{tabular}{llllll}
\hline Statements & $\mathrm{N}$ & Minimum & Maximum & Mean & Std. Deviation \\
\hline a27 & 68 & 1 & 5 & 4.01 & 1.099 \\
a28 & 66 & 1 & 5 & 3.18 & 1.498 \\
a29 & 68 & 1 & 5 & 2.68 & 1.263 \\
a31 & 67 & 1 & 5 & 2.85 & 1.351 \\
a32 & 68 & 2 & 5 & 4.09 & 1.047 \\
\hline
\end{tabular}

Statement 27, teaching English at an early age has an influence on children's cultural identity, revealed strong agreement among the participants $(\mathrm{N}=68)$, with a Mean of 4.01. The participants showed moderate agreement with statement 28, my positive or negative attitudes, as a parent, towards the western culture affect my child's English learning, giving a Mean score of 3.18. In other words, the participants $(\mathrm{N}=66)$, to some extent, agreed that their positive or negative attitudes towards the western culture can affect their children's learning of English. The participants in their response to statement 29, I find that English has affected my child's Arabic language, revealed that they slightly agreed, with a Mean of 2.68. This implies that not all of the participants appeared to agree that English has affected their 
children's Arabic language. In a similar manner, Statement 31, the preference of many parents of the English language for their children has a negative impact on the status of the Arabic language and its functions, showed that the participants slightly agreed with a Mean score of 2.85. In this sense, the majority of participants did not appear to agree that the English language has a negative impact on the status of the Arabic language and its functions. For statement 32, Saudi government should increase the status of Arabic in the society, the participant's revealed a strong agreement with a Mean score of 4.09, suggesting that most of them support the idea that the status of Arabic should be increased in the society and it is the responsibility of the Saudi government to do so. The findings are illustrated in Figure 6, showing that $22,05 \%$ of the participants scored between 4 and 5 , among them $19.11 \%$ between 4.20 and 5 .

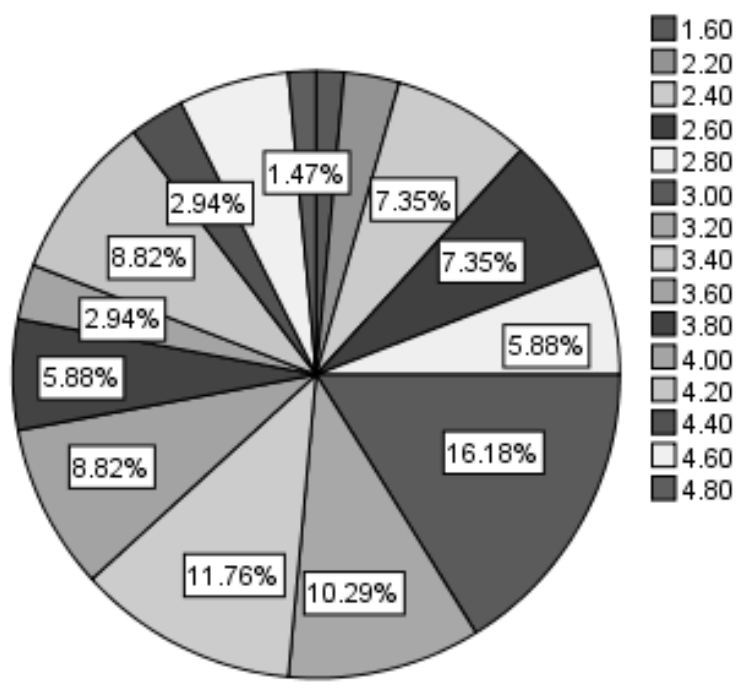

Figure 6. Distribution of scores total for attitudes towards the effect of EMI on children's Arabic language and culture

Finally, the above tables and figures, with the norms (Strongly disagree =1-1.8), (Disagree=1. 8-2.6), (Somewhat agree $=2.6-3.4),($ Agree $=3.4-4.2),($ Strongly agree $=4.2-5)$, showed that:

1. Parents 'attitudes towards using EMI in international private schools at an early age were positive.

2. There were positive effects of using EMI on children educational achievement in the next levels. However, parents' slightly agreed that the English language has affected the children's Arabic language.

3. Many Saudi parents choose to send their children to EMI international private schools at an early age, because:

- The children who study in EMI schools are better than those in public schools.

- Arabic and English can both be used as mediums of instruction which is more useful (statement 20).

- EMI international private schools teach all subjects in English which increases the child's proficiency in English.

\subsection{Results of Content Questions}

The survey included three content questions. The first asked for parents' attitude towards English in general. The second asked for the effects of the English language on the child's Arabic language. The last one solicited their opinions concerning the reasons behind the preference of many Saudi parents for sending their children, at an early age, to international private primary schools where English is the medium of instruction. Answers to the first question were classified under three subsections related to various attitudes, such as the most important language in the world, international language, and favorite language. For the second question, parents' answers were categorized under three subsections: English didn't influence the child's Arabic language, English negatively influenced the child's Arabic language, and English positively influenced the child's language. For the third question, participants' answers were classified under five thematic categories: importance of English as an international language, the effectiveness of early access to English, opportunity to get a job in the future, English is given priority and satisfaction with the quality of education in general.

\subsection{Parents' attitudes towards English language in general}

The first open-ended question stated as "What is your attitude towards English in general?" received a response rate of $99 \%$, i.e., almost all of the participants answered the question. The most frequent answer given by the participants was that the English language is an important language because it is the language of the world, with 30 responses emphasizing this point. One male participant, who has an advanced level in English, said "It's an important language in order to know what is happening in the world around us". The vast majority expressed their positive attitudes towards the English language as an international language. For example, one male participant, who has an advanced level in the language, pointed out, "it is an easy language and an international one. It is considered the key for learning 
because most of the scientific resources are available in English." Also, another female participant, who has an intermediate level in the English language, claimed that "English is the first international language and the most widely spread language around the world." Twenty participants expressed their positive attitude towards English as their favorite language. A female participant, who has an advanced level in English language, said "I like English more than Arabic." Another female participant, who also has an advanced level in English language, stated "I like to speak in English." Overall, participants' attitudes towards English were positive. They were aware of the importance of the English as an international language.

\subsection{The effects of the English language on the child's Arabic language}

Participants were given the following statement "I find that English has affected my child's Arabic language.", and were requested to express their agreement or disagreement and then explain the following question "How did learning English influence your child's Arabic language?" Seventy-one percent of the participants (N=68) offered their responses with justifications to back them up. The responses show that $7 \%$ of the 68 of the participants who responded strongly agreed, $13 \%$ agreed, 54\% revealed opinions between agreement and disagreement, and 26\% strongly disagreed.

Fifteen out of sixty-eight participants provided their explanations for the question "How did learning English influence your child's Arabic language?" Participants' explanations for their choices were analyzed and classified under three thematic categories. While twenty-one of participants said there was no influence of English on the child's Arabic language, the majority of participants (twenty- four) explained that English has negatively influenced their child's Arabic language. According to the participants' explanations, there are ten negative effects of English on the child's Arabic language. The first effect is the difficulty in understanding Arabic vocabulary or finding the right word while speaking, because Arabic is not given much attention from private schools. A female participant, who has an advanced level in English, made the following remark "Names for origins, planets, months, and many other names are unknown to my child." Additionally, one male participant, who has an advanced level in English, claimed "My child doesn't know many Arabic words which makes him feel embarrassed in front of his grandparents and the rest of the family." The second effect is related to weakness in witting and reading skills in Arabic. The child is not fluent and commits a lot of spelling mistakes in the Arabic language. For example, a female participant, who has an advanced level in English, pointed out that her daughter "In writing, she writes from left to right as in English and even in writing Arabic numbers she gets confused. She writes number four in Arabic as (3)." The third effect is preference of English over Arabic. A male participant, who has an advanced level in English, said "My child's prior interest is English, and then comes later the Arabic language." The fourth effect is hatred of Arabic Language, especially if English was learned first, because the child finds it difficult to learn English. One female participant stated about her child "She thinks that Arabic is a boring language. She prefers to express herself in English." The fifth effect is negligence of Arabic courses, especially in the early stages, and attention is given to English courses. For example, one female, who has an intermediate level in English, said "More focus is on English because all subjects are taught in English. Only two subjects are taught in Arabic, these are the Arabic subject and the Islamic education subject." The sixth effect is that English is used more than Arabic because the child had lived abroad. One female participant said "My daughter was born while I was abroad, so, she uses English mostly." Another female participant claimed about her child "She struggles with the Arabic subject because she had lived and studied abroad." The other negative effects are weakness in Arabic composition, weakness in Arabic pronunciation, weak in Arabic literary skills, e.g., storytelling, and using a lot of English words while speaking in Arabic, i.e., mixing English and Arabic words during speech.

Four out of fifteen participants said that English has a positive influence on the child's Language. For example, a female participant stated that "My child has become more culturally and scientifically educated. He is more capable of following advances in technology and science. His ideas and skills have improved."

5.5 Main Reasons behind the Preference of Saudi Parents for sending their Children to EMI International Private Primary Schools

The last open-ended question stated as "In your opinion, why do many Saudi parents choose to send their children to EMI international private primary schools at an early age? What are the reasons?" received a response rate of $87 \%$. Participants' answers were classified under five thematic categories: importance of English as an international language, the opportunity to join university and get a job in the future, the effectiveness of early access to English, English is given priority and satisfaction with the quality of education in general. The most frequent reason given by the participants was the importance of English as an international language. The majority wanted to send their children to EMI international private primary schools because they recognize the status of English as international global language. For example, one female participant who has an advanced level in English, said "English becomes the language of the whole world. It will be essential in the future life." Another female participant stated "It is the language of the globe, the language of communication, the language of work and the language that builds the individual's personality and identity." Also, one female participant said "It is the language of science, technology, and computer. It's a means of communication and a key for acknowledging the foreign culture."

Fourteen out of sixty one participants stressed the significance of English to provide more opportunities to join university and to get a better job in the future. A male participant, who has an intermediate level in English, claimed "It is because most of the scientific fields, such as medicine, engineering, and pharmacy are taught in English. Also, these schools can prepare children in the long run, after graduation, to complete their education abroad." Additionally, a 
female participant, who has an advanced level in English, said "English becomes a necessary requirement needed for applying for a job."

Further, ten participants expressed the effectiveness of early access to English, with some participants claiming "Early Start, Growing Smart." One male participant, who has an advanced level in English, said "Because learning at an early age has positive effects, regarding children's capacity for understanding and memorization." Four responses supported the teaching of English in EMI private schools at an early age because Saudi public schools teach English in later stages.

Three responses stressed their satisfaction with the quality of education in EMI international private primary schools where English is given priority. For example, one female participant, who has an advanced level in English, stated "Many parents prefer EMI private schools for their children because public schools don't provide the same quality of education in EMI private schools and English is not emphasized."

\section{Discussion}

The above results can be interpreted under six main themes that manifest Saudi parents' attitudes towards using EMI in primary private schools. That is to say, it attempted to examine Saudi parents' attitudes towards the importance of English for their children, primary level as the suitable age for their children to learn English, reasons of learning English at an early age (primary level), using EMI in private primary schools, the effect of EMI on children's educational achievement in next levels, and the effect of EMI on children's Arabic language and culture.

\section{Main themes}

6.1 The Importance of English for Children. The Participants' responses to the items under the construct parents' attitudes towards the importance of English for their children indicated strong agreement among the participants. They expressed positive attitudes towards English in general. They appeared to admit that it is important for their children to learn English language, emphasizing its importance as a global language. This is consistent with the finding of Thirunavukkarsu (2011) who claimed that parents understand the importance of English because it provides better opportunities for their children. They think that high proficiency in English opens new gates to fulfill the demands of the globalized world.

6.2 Primary Level as the Suitable Age for Children to Learn English. Parents stressed the significance of learning English at an early age, starting from first grade in primary schools. They expressed a belief that children who learn English at an early age (from seven years old) are better than those who learn it at ten or above. They also believe that the earlier the child learns English the easier it will be to acquire the language. Generally, participants had strong positive attitudes towards learning English at an early age from primary level.

6.3 Reasons of learning English at an Early Age. The responses of the participants for the items under the construct reasons of learning English at an early age (primary level) revealed moderate agreement of the importance of English in terms of employment and high social status. This result is compatible with that of Peresuh, M., and Mashukn (2012), who reported that most parents in Zimbabwe think of English as a way to reach employment and education is equated to the proficient use of English. However, participants strongly agreed that knowledge of English is a requirement of success in life, and that it will help their children to avoid communication problems with others in the future, e.g., travelling abroad. The reasons of learning English at an early age were further reinforced by participants' answers to the open-ended question, asking them why they choose to send their children to EMI private primary schools, where English is the medium of instruction. The most frequent reason was the importance of English as an international language. The second reason was the significance of English to provide more opportunities for joining universities and getting better jobs in the future, indicated by 40 participants. The third reason given by the participants was the effectiveness of early access to English. Other responses mentioned satisfaction with the quality of education in EMI international private primary schools where English is given priority. These reasons imply that parents are aware of English status as a global language that will provide a wide range of opportunities for their children in the future. They regard English as beneficial for better jobs and it will allow their children to pursue their graduate studies at foreign universities. Thus, they prefer private primary schools, where children are exposed to English at an early age, because English is given priority in these schools.

6.4 Using EMI in private primary schools. Two items under this construct were sought to elicit participants' attitudes towards the influence of the family's socio-economic status on their choice of EMI private primary schools. The results showed that family income and parental occupation can influence the parents' choice of EMI private primary schools for their children. They strongly agreed that it is better for their children to join EMI private primary schools. They appeared to support bilingual instruction where both Arabic and English are used as mediums of instructions. This finding is in agreement with Youssef and Simpkins (1985) as cited in Al-Hussein (2004), who reported that 90\% of Arab parents supported their children's bilingual education, and wanted them to continue with these programs. In addition, participants expressed a belief that EMI private schools are better than public schools. Participants wanted all subjects to be taught in English in order to increase their children's proficiency in English. All in all, the participants expressed positive attitudes towards EMI private primary schools over public schools.

6.5 The Effect of EMI on Children's Educational Achievement in Next Levels. Participants' attitudes towards the effect of EMI on children's educational achievement in next levels were positive. They believed that learning English at an early age will influence positively their children's success in the later stages, understanding capacity, and cultural awareness. They related a higher level of performance and academic achievement in next levels with EMI, i.e., children 
who study using EMI achieve a higher level of performance and academic achievement than those who use Arabic as a medium of instruction. This indicates that parents perceive EMI as factor to obtain a higher level of performance and academic achievement in the next levels.

6.6 The Effect of EMI on Children's Arabic Language and Culture. According to the participants' responses to items under this construct, participants' positive or negative attitudes towards the English language and the western culture can influence their children's attitudes. The participants in their response to statement 29, I find that English has affected my child's Arabic language, revealed that they slightly agreed, with a Mean of 2.68. The qualitative results seemed to confirm this finding. While $42 \%$ out of 50 of the participants said that English didn't influence their children's Arabic language, 48\% claimed that English has negatively influenced their children's Arabic language. For example, difficulty in understanding Arabic vocabulary, weakness in writing and reading skills in Arabic, preference of English over Arabic, hatred of Arabic Language, negligence of Arabic courses, weakness in Arabic composition, weakness in Arabic pronunciation, weakness in Arabic literary skills, e.g., storytelling, and using a lot of English words while speaking in Arabic, i.e., mixing English and Arabic words during speech.

\section{Conclusions and Pedagogical Implications}

Generally, parents' attitudes towards using EMI in international private primary schools were positive in this study. Many Saudi parents prefer to send their children to EMI private primary schools, because they realize the importance of English as an international language, which can provide better opportunities for their children in the future. Also, they prefer to send their children to these schools, where English is used as a medium of instruction, because it is more effective if the child learn the language at an early age. However, some parents expressed a belief that English has negatively affected their children's Arabic language.

The previous facts imply that parents value the learning of English for their children, which leads them to choose EMI international schools over public schools. Some participants mentioned in their open-ended responses that they are satisfied with the quality of teaching in EMI schools, in which English is given priority. This may indicate to some extent a dissatisfaction of English teaching in public schools. Thus, further research is needed to investigate this finding.

Furthermore, the findings of the study raise issues related to language planning and policy in EMI schools which can be addressed by the Saudi Ministry of Education, namely the medium of instruction in these schools, and maintenance of the children's Arabic language. The majority of participants strongly supported the idea of using both Arabic and English as mediums of instruction. These issues can be solved first by raising awareness of the status of the Arabic language in the society which is the responsibility of the Saudi government. Then, the Saudi Ministry of Education should adopt a policy of bilingual education, where both Arabic and English are used as mediums of instruction in EMI schools in order to maintain children's Arabic language instead of using EMI only.

To conclude, hopefully, the present study has contributed to the area of research related to early language learning and language planning and policy.

\subsection{Limitations of the Study and Recommendation for Future Research}

Although, this study has come up with some preliminary findings, it has its own limitations in terms of its design. The survey was distributed to Saudi parents who have their children studying in "Talla'aAlmostagbal" international private primary school in the Southern region of Saudi Arabia, Abha, and the researcher had no control over the number of the participants and their gender. Out of 100 questionnaires distributed by the researcher, only 68participants returned their questionnaires. Therefore, the gender distribution was not balanced with 12 male and 55 female respondents. The imbalance of gender is due to the fact that the school was a female school, i.e., all students and educators are females. Also, it is because mothers are more caring about their children's education than fathers, especially at early stages of school.

Additionally, the instrument, a closed-question questionnaire, also has its limitations. The majority of the survey questions was measured on a scale of 5 points of agreement and disagreement, which does not provide a full understanding of issues of interest. In this sense, the study's findings are considered preliminary and a follow up study might be needed. Other research methods, like interviews can be used to provide more in-depth insights into parents' reasons for sending their children to EMI international private primary schools at an early age.

Finally, the study only investigated the attitudes of 68 Saudi parents who have their children studying in "Talla'aAlmostagbal" international private primary school in the Southern region of Saudi Arabia, Abha. The results may not be the same with all Saudi parents elsewhere. So, it may not be appropriate to generalize the findings to all Saudi Parents.

\section{References}

Ahmed, K. (2010). The Arabic language: Challenges in the modern world. International Journal for CrossDisciplinary Subjects in Education (IJCDSE), 1(3), 283-292.

Al- Abdaly, A. H. (2012). The impact of English as a medium of instruction on science learning: Perception of the medicine female students and academic staff at King Khalid University (master's thesis). Riyadh, Saudi Arabia.

Al- Hussein, A., M. (2004).Saudi parents' attitude towards their children learning English as a second language in the United States. Retrieved from http://v3.educonv.com/docs/index-437586.html 
Cummins, J. (2001). Linguistic interdependence and educational development of bilingual children. In C. Baker \& N. Hornberger (Eds.), an introductory Reader to the Writing of Jim Cummins (pp. 63-95). Clevedon: Multilingual Matters.

Davis-Kean \& Schnabel, K. U. (2001). The impact of socio-economic characteristics on child outcomes: The mediating role of parents' beliefs and behaviors. Child Development, Under review, in Feinstein, L. Duckworth, K, \& Sabates, R. (2004). A Model of the Intergenerational Transmission of Educational Success. Wider Benefits of Learning (Report No.10). Retrieved from http://eprints.ioe.ac.uk/5977/1/Feinstein2004amodel.pdf

Ebad, R. (2014). The role and impact of English as a language and a medium of instruction in Saudi higher education institutions: Students-instructors perspective. Study in English Language Teaching, 2 (2), 142-143. Retrieved from http://www.scholink.org/ojs/index.php/selt/article/download/170/18

Fillmore, L. W. (1991). When learning a second language means losing the first. Early Childhood Research Quarterly, 6 (3), 323-346. Retrieved from JSTOR database.

Fillmore, L.W. (2000). Loss of family languages: Should educators be concerned? Theory into Practice, 39 (4), $203-$ 210. Retrieved from http://bama.ua.edu/ jpetrovi/bef585/fillmore.pdf

Gutman, L.M. \&Akerman, R. (2008).Determinants of aspirations. Center for Research on the Wider Benefits of Learning (Report No. 27). Retrieved from http://eprints.ioe.ac.uk/2052/1/Gutman2008Determinants.pdf

Hanani, F. (2009). Impact of English on young Arabs' use of Arabic in the UAE: A Thesis in teaching English to speakers of other languages (master's thesis). Retrieved from https://dspace.aus.edu/xmlui/handle/11073/75

Kachru, B., Kachru, Y., \& Nelson, C. (2006). The handbook of world Englishes. Oxford: Blackwell.

Mouhanna, M. (2010). The medium of instruction debate in foundation math and IT. What's the Role of L1? UGRU Journal, fall issue, 1-15.

Peresuh, M., \&Mashukn, J. (2002). The Role of the primary language in the bilingual-bicultural education in Zimbabwe.Zambezia, XXIX (i), 1-11. Retrieved from http://san3.lib.msu.edu/DMC/African Journals/pdfs/Journal of the University of Zimbabwe/vol29n1/juz029001004.pdf

Phillipson, R., \&Skutnabb-Kangas, T. (1996). English only worldwide or language ecology? TESOL Quarterly, 30(3). Retrieved January 12, 2014, from http://www.rnld.org/sites/default/files/Phillipson\%20and\%20SkutnabbKangas\%201996.pdf

Sammons. (2007). EPPE 3-11 influences on children's development and progress in Key Stage 2: Social/behavioral $\begin{array}{llllll}\text { outcomes in } & \text { Year Report } & \text { No. RR007). }\end{array}$ http://webarchive.nationalarchives.gov.uk/20130401151715/http://www.education.gov.uk/publications/eOrderingDown load/DCSF-RR007.pdf

Thirunavukkarsu, K. (2011). Reintroduction of English as medium of instruction in Sri Lanka: With a special reference to Jaffna. International Journal of English Language and Literature Studies, 1(1), 1-8. . Retrieved from http://www.aessweb.com/pdf-files/ijells, pp. 1-8.Pdf 